\title{
$\gamma$-Ray Induced Metastable Defects in Mn-Doped Lead-Phosphate Glass
}

\author{
F. Ezz-Eldin, E. Antar* and M. A. Elahdal* \\ Radiation Chemistry and ${ }^{*}$ Radiation Protection and Dosimetry \\ Dept., National Centre for Radiation Research and Technology \\ (NCRRT), P. O. Box; 29 Nasr City, Cairo, Egypt. \\ E.mail:anter_protect@yahoo.com.
}

\begin{abstract}
DbO- $\mathrm{P}_{2} \mathrm{O}_{5}+\mathrm{xMnO}_{2}(0<\mathrm{x}<1)$ glasses are synthesized. The effects of $\mathrm{MnO}_{2}$ on structural and optical properties of glasses have been investigated using different characterization techniques. The effect of both glass composition and $\mathrm{MnO}_{2}$ content on the generation of radiation-induced defects has been investigated. The intensity and the position of the induced bands are found to depend on the type and composition of glass, concentration of the dopant and also on the irradiation dose. Experimental results indicate that the undoped glass reveals before irradiation strong and broad ultraviolet absorption which is related to the co-sharing of absorption due to both trace iron impurities and lead ions $\left(\mathrm{Pb}^{2+}\right)$. The band gap energy is found to decrease with the increasing content of $\mathrm{MnO}_{2}$ in the glasses, while different irradiation doses showed remarkable effect on the band gap which decreases to semi conducting range. The effect of gamma irradiation also takes place, the band gap decreases from 4.15 to $2.9 \mathrm{eV}$ and from 3.84 to 2.8 for indirect transition for both G1 and G4 respectively also for all glass systems.

Keywords: Lead-phosphate glass, gamma-irradiation, optical absorption, optical energy gap.
\end{abstract}

During the past two decades, phosphate glasses have been investigated extensively and it is because of the interesting developing new glasses suited to the demands of both industry and technology, because of their low glass transition temperatures, low optical dispersions and relatively high thermal expansion coefficient (Doweidar et al., 2005). However, the poor chemical durability, high hygroscopic and volatile nature of phosphate glasses is preventing them from replacing the conventional glass in a wide range of technological applications. Some phosphate glass properties make them hopeful candidates for fast ion conducting material, biomedical applications and bio-compatible materials such as that found in bone regeneration application and shielding materials. 
Limited literature is available for the replacement of glass network former $\left(\mathrm{P}_{2} \mathrm{O}_{5}\right)$ by intermediate oxide; $\mathrm{MnO}_{2}$ and its effect on the properties of glasses (Saif et al., 2013). The present work reports UV-visible absorption spectral measurements of base undoped lead phosphate glass of equimolecular composition (50mol \% $\mathrm{PbO}, 50 \mathrm{~mol} \% \mathrm{P}_{2} \mathrm{O}_{5}$ ) and with also some other samples containing the same base composition together with $0.05,0.1,0.25$ and 0.75 $\mathrm{MnO}_{2}$ and named as G1,G2,G3,G4 and G5 respectively. The work also includes the same UV-visible spectroscopic measurements after subjecting the prepared samples to successive gamma irradiation doses. A further objective of this work is to find out the radiation-induced defects generated from the undoped and Mndoped lead phosphate glasses. A final goal is aimed to evaluate the suitability of such glasses as gamma-ray indicators.

\section{Materials and Methods}

\section{Preparation of the glasses}

The glass samples were prepared by using chemically high purity grade raw materials. Lead oxide was added in the form of pure lead oxide $\left(\mathrm{Pb}_{3} \mathrm{O}_{4}\right)$ and $\mathrm{P}_{2} \mathrm{O}_{5}$ was introduced as pure ammonium dihydrogen phosphate $\left(\mathrm{NH}_{4} \mathrm{H}_{2} \mathrm{PO}_{4}\right)$ and $\mathrm{MnO}_{2}$ was added in the form of its respective pure oxide. Each batch weighs about $50 \mathrm{~g}$ was melt in porcelain crucibles by placing them in an electrical furnace for an hour, at $800^{\circ} \mathrm{C}$ for 1 hour till a bubble free liquid was formed. These melts were rotated several times and the homogenized melts were poured in slightly warmed stainless steel molds of the required dimensions. The prepared glasses were annealed at $200^{\circ} \mathrm{C}$ for $3 \mathrm{~h}$ to reduce thermal stress, and cool down to room temperature $\left(\sim 25^{\circ} \mathrm{C}\right)$. All glass samples were cut and polish in proper shape for further studies.

\section{$U V$-visible absorption measurements}

The optical absorption of highly polished samples of the undoped and Mndoped glasses of the dimensions $1 \times 4 \times 0.2 \mathrm{~cm}^{3}$ were recorded at room temperature before and after each successive gamma doses by a recording spectrophotometer in the range 200-1000nm type Perkin-Elmer.

\section{Gamma irradiation facility}

$\mathrm{A}^{60} \mathrm{Co}$ gamma cell $(2000 \mathrm{Ci})$ was used as a gamma-ray source with a dose rate of $1.5 \mathrm{~Gy} / \mathrm{second}$ at a temperature of $\sim 30^{\circ} \mathrm{C}$. The investigated glass samples

Egypt. J. Rad. Sci. Applic., Vol. 26, No. 1-2 (2013) 
were subjected to the same gamma dose every time. Using a Fricke dosimeter, the absorbed dose in water was utilized in terms of dose in glass. No cavity theory corrections were made. Each glass was successively subjected to a totally dose of 0.3 and finally to $30 \mathrm{kGy}\left(10^{6} \mathrm{Rad}=10^{4} \mathrm{~Gy}\right)$.

\section{Results and Discussion}

Fig. 1. illustrates the UV-visible absorption spectrum of the base lead phosphate glass before irradiation. The spectrum reveals strong and broad UV absorption extending from 200 to about $300 \mathrm{~nm}$ with a quite sharp band at about $250 \mathrm{~nm}$ and with a secondary kink in ascending lobe at about $215 \mathrm{~nm}$. With increasing $\mathrm{MnO}_{2}$ content the induced spectra are generally characterized by some low intense two peaks at $\sim 400$ and $480 \mathrm{~nm}$. On subjecting the base undoped glass to successive gamma irradiation, the intensity of the UV sharp band is observed to progressively increase with shifting of the peak to longer wavelength reaching about $275 \mathrm{~nm}$ in the highest dose and no induced visible band is observed.

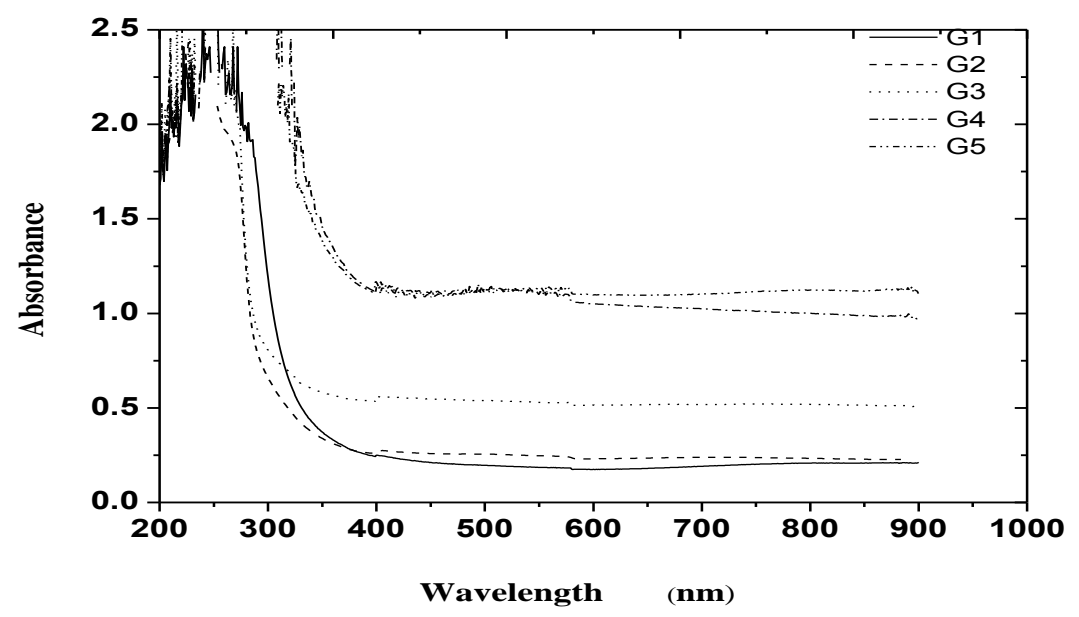

Fig. 1. Absorption spectra of glasses G1, G2, G3, G4 and G5 before irradiation.

\section{$U V$-visible absorption spectra of $\mathrm{MnO}_{2}$-doped glasses before and after irradiation}

Fig. 2-6. illustrate the absorption spectra of different concentrations of Mndoped glass samples before and after successive irradiation doses. The absorption Egypt. J. Rad. Sci. Applic., Vol. 26, No. 1-2 (2013) 
spectra of the Mn-doped samples reveal primarily strong UV absorption previously identified in the undoped host lead phosphate glass and also show low intense broad band (340-520nm). The intensities of the induced bands are observed to fall at the first irradiation dose $(0.3 \mathrm{kGy})$ and then a remarkable increase in the peaks intensities was observed with successive irradiation.

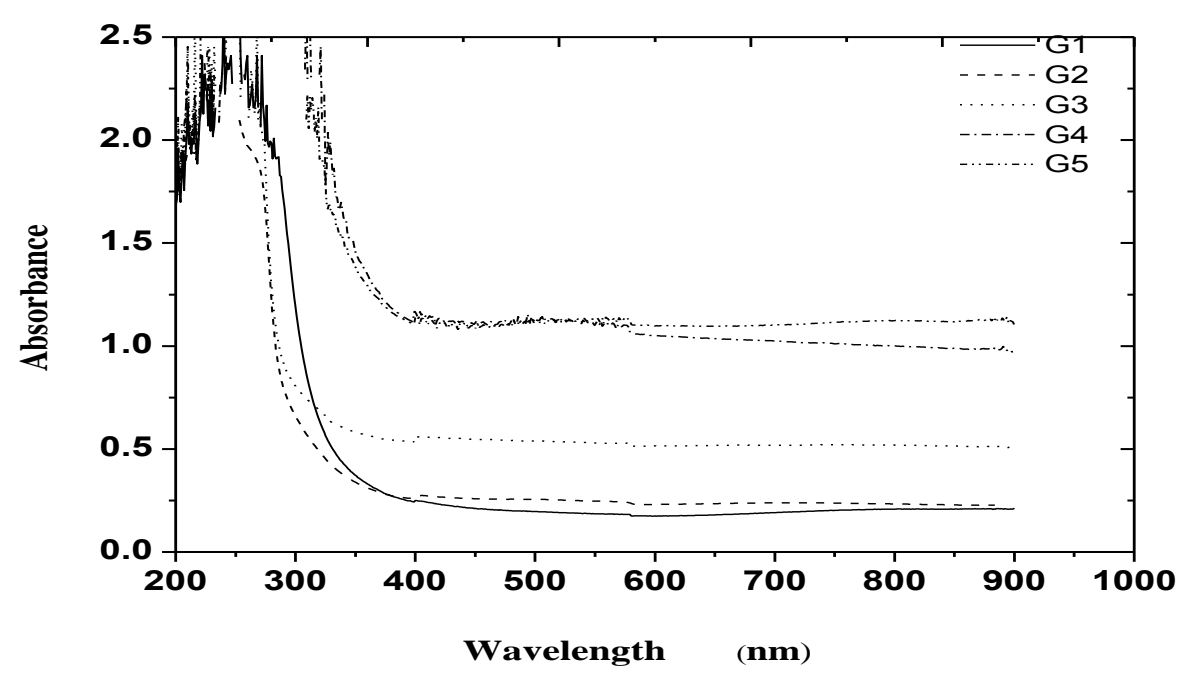

Fig. 2. Absorption spectra of glass G1 before and after irradiation.

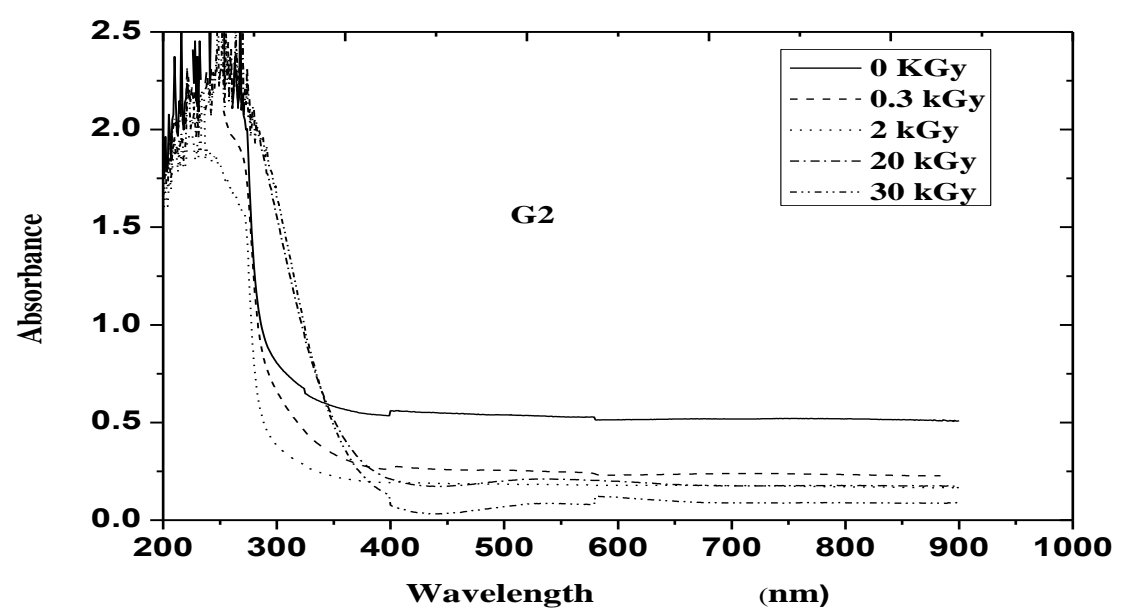

Fig. 3. Absorption spectra of glass $\mathbf{G} 2$ before and after irradiation.

Egypt. J. Rad. Sci. Applic., Vol. 26, No. 1-2 (2013) 


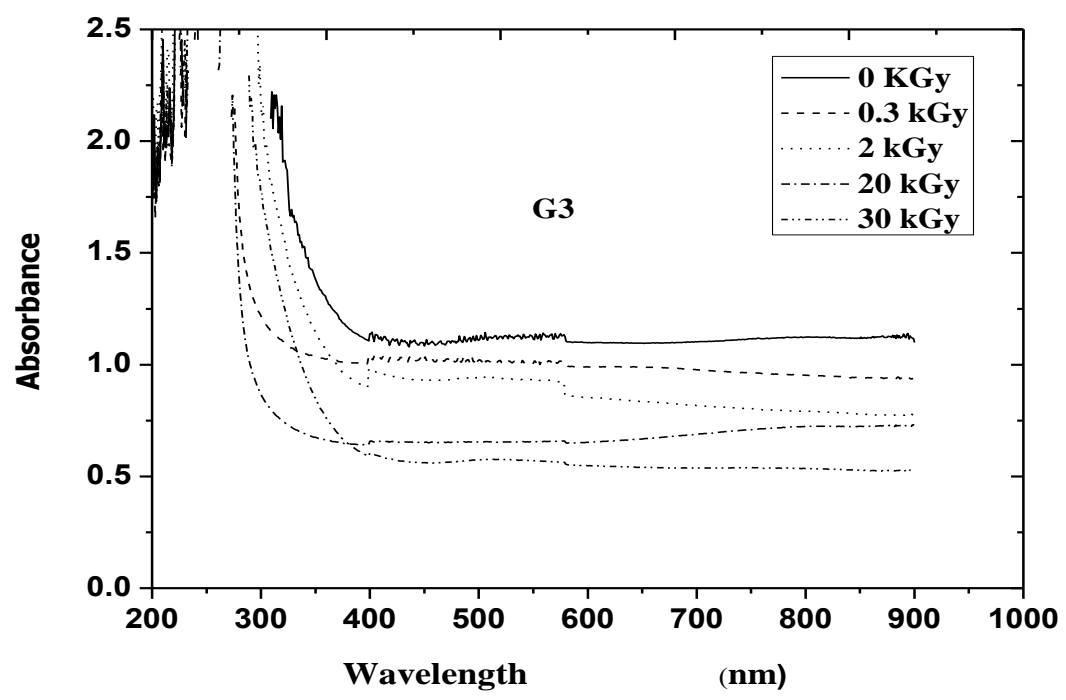

Fig. 4. Absorption spectra of glass G3 before and after irradiation.

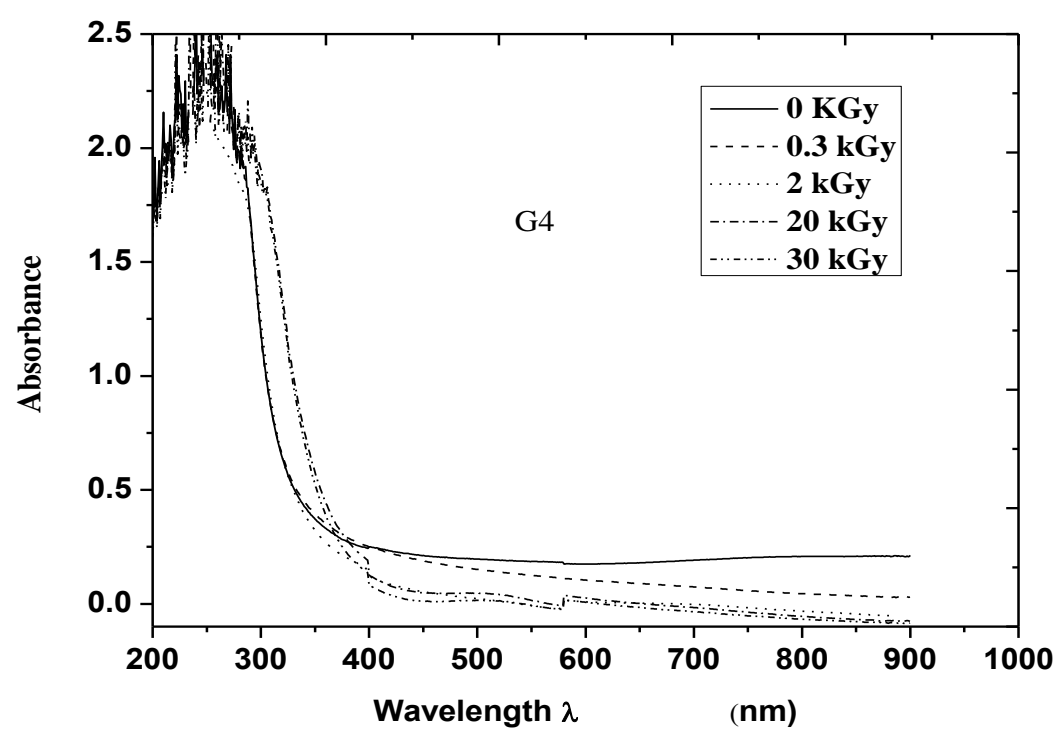

Fig. 5. Absorption spectra of glass G4 before and after irradiation.

Egypt. J. Rad. Sci. Applic., Vol. 26, No. 1-2 (2013) 


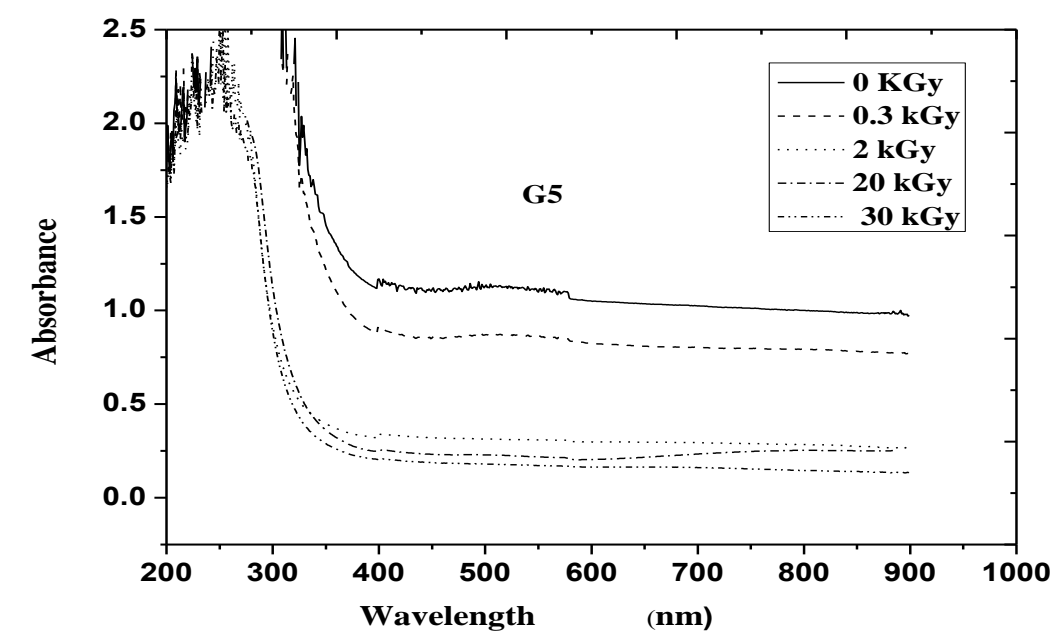

Fig. 6. Absorption spectra of glass G5 before and after irradiation.

\section{Origins of the $U V$-visible in the host lead phosphate glass}

The present studied base glass is of the composition $\left(\mathrm{PbO} 50 \mathrm{~mol} \%, \mathrm{P}_{2} \mathrm{O}_{5}\right.$ $50 \mathrm{~mol} \%$ ) and reveals a broad UV spectrum which is more widely extended than that previously shown in various alkali phosphate glasses (Marzouk et al., 2006). So, it is suggested that the observed broad ultraviolet absorption observed in high lead phosphate glass originates from the co-sharing of absorption due to both trace iron impurities and that due to $\mathrm{Pb}^{2+}$. The distinction between the spectrums of each of those partners necessitates further work by combined techniques and utilizing special extra pure raw materials.

Extensive radiation effects in alkali and alkaline earth phosphate glasses have been early reviewed by Lell et al. (1966). Bishay (1970) showed that the induced absorption can be resolved into four bands centered at $2.3 \mathrm{eV}(\sim 540 \mathrm{~nm})$, $2.9 \mathrm{eV}(\sim 420 \mathrm{~nm}), 5.5 \mathrm{eV}(\sim 225 \mathrm{~nm})$, and $6.0 \mathrm{eV}(\sim 200 \mathrm{~nm}$. Ghoneim et al. (2013) proposed two models, one for the $2.3 \mathrm{eV}(\sim 540 \mathrm{~nm})$ centre with a hole trapped in a pair of (NBO's) with the alkali covalently bonded to the oxygen (colour centre II): Beekenkamp assumed that the band at $6.0 \mathrm{eV}(\sim 200 \mathrm{~nm})$ is due to oxygen vacancy in $\mathrm{PO}_{4}$ tetrahedron which trapped two electrons. The induced band near $5.1 \mathrm{eV}(\sim 245 \mathrm{~nm})$ seems to correlate with the $4.8 \mathrm{eV}(\sim 275 \mathrm{~nm}) \mathrm{P}_{2}$ defect band in P-doped silica which arises from an electron trapped in an antibonding Egypt. J. Rad. Sci. Applic., Vol. 26, No. 1-2 (2013) 
orbital of a $\mathrm{PO}_{4}$ unit, which has no analog in silicate glasses. Also, gamma irradiation is observed to produce high intensive effects on alkali phosphate and other mentioned glasses. It can thus assumed that the presence of high $\mathrm{PbO}$ content $(50 \mathrm{~mol} \%)$ in the studied lead phosphate glass suppress to a measurable value the effects of successive gamma irradiation, especially in the visible region and with the combined presence of phosphate partner. El-Batal et al., 2009) have recently showed that high lead silicate glasses and high lead borate glasses reveal some shielding effects towards successive irradiation doses but showing induced visible bands. Such results indicate the complete shielding of induced visible bands in the host lead phosphate glass virtually originates from the sharing of both partners, namely, phosphate and lead oxide. It seems that the shielding behaviour as illustrated by the absence of induced visible bands saves sufficient positive holes to perform this photochemical reaction. The observed shift of the UV induced from 250 to $275 \mathrm{~nm}$ by gamma irradiation is correlated to the possible distortion of the iron species symmetry responsible for this band through gamma irradiation.

\section{$U V$-visible in the lead phosphate glass doped $\mathrm{MnO}_{2}$}

The Mn-doped glass reveals UV spectrum and no visible bands could be identified (Fig. 2-6). It is well known that, manganese is accepted to exist in two valence states in glasses, namely, the trivalent $\mathrm{Mn}^{3+}$ state and the divalent $\mathrm{Mn}^{2+}$ state. Trivalent manganese ions exhibit a broad visible band centred at 480$520 \mathrm{~nm}$ while the divalent manganese ions belong to $\mathrm{d}^{5}$ configuration for which there are no spin-allowed transitions possible and only weak peaks may occur corresponding to the spin-forbidden transitions (Weyl, 1959).

The absence of the characteristic visible broad band due to $\mathrm{Mn}^{3+}$ in this glass supports our assumption that the base lead-phosphate host glass initiates the low valence state and $\mathrm{Mn}^{3+}$ ions are not obviously identified in noticeable percent. On subjecting this Mn-doped glass to gamma irradiation, the induced broad band at $540 \mathrm{~nm}$ can be assigned to an induced state of $\left(\mathrm{Mn}^{3+}\right)$ or metastable $\left(\mathrm{Mn}^{2+}\right)^{+}$ions which are previously suggested by (Monke et al., 2001) to be generated by capturing $\mathrm{Mn}^{2+}$ ions to positive holes through photochemical reaction. A similar behaviour for $\mathrm{Mn}$ ions in different glass systems was reached by various workers (Ghomeim et al., 1983). It is accepted that Paul (1982), glass Egypt. J. Rad. Sci. Applic., Vol. 26, No. 1-2 (2013) 
always contains traces of iron impurities and when a glass is decolorized with manganese and exposed to $\gamma$-irradiation, electrons are expected to be shared between $\mathrm{Mn}^{2+}$ and $\mathrm{Fe}^{3+}$ and takes place as follows: $\mathrm{Fe}^{3+}+\mathrm{Mn}^{2+}+h v \leftrightarrow \mathrm{Fe}^{2+}$ $+\mathrm{Mn}^{3+}$. Thus after irradiation the near-ultraviolet absorption will decrease (due to decrease of $\mathrm{Fe}^{3+}$ ) and the glass will appear pink. Thus the interference of $\mathrm{Fe}_{2} \mathrm{O}_{3}$ absorbs radiation and cause discoloration of glass (causing the remarkable decrease the absorption intensity absorption).

Besides the above previous interpretation, the continuous observed dramatic decrease in intensity of the visible absorption spectra (350-800nm) for the studied glasses after been exposed to different irradiation doses can be explained as follows: the origin of this negative induced absorption may be attributed to the distraction of non-bridging oxygen by the irradiation, which would cause the absorption edge to shift to shorter wavelength.

\section{Interpretation of the fading behaviour}

\section{Bleaching of the irradiated glasses}

Fig. 7. shows the fading behaviour of the glasses studied after been irradiated up to $30 \mathrm{kGy}$ within interval times ranging from 1 to 30 days at room temperature $\left(\sim 25^{\circ} \mathrm{C}\right)$. It can be concluded that the intensity of the peak at $\sim 400 \mathrm{~nm}$ decreases with increasing the bleaching time. Also, the intensity either increase or decrease with varying the $\mathrm{MnO}_{2}$ concentration. Generally, both the increase and the decrease in the peak intensity are very limited. The fading behavior illustrated in Fig. 7 shows that the spectral curves within the interval of time studied (up to 60 days) remain almost unchanged and very close in the undoped and high content $\mathrm{MnO}_{2}$-doped samples which appear in the case of G1 and G5.

This indicates the shielding or persistence of the studied lead-phosphate glasses especially that containing high $\mathrm{MnO}_{2}$ content. Several authors have arrived to the conclusion that phosphate glasses and especially that containing transition metals show shielding behaviour towards successive gamma irradiation doses (El-Batal et al., 2011). It is obvious that the combined presence of phosphate anions in the mentioned glasses besides the sharing of transition metal ions causes the observed shielding behaviour. Further work is still needed for varieties of phosphate glasses doped with transition metal ions to justify the processes of

Egypt. J. Rad. Sci. Applic., Vol. 26, No. 1-2 (2013) 
shielding, fading and thermal recovery of induced defects. The phenomena of irradiation can be made reversible (Marzouk et al., 2006); when a piece of irradiated manganese glass is bleached at room-temperature, the colour bleaches and the absorption spectrum becomes similar to that of the unexposed glass.

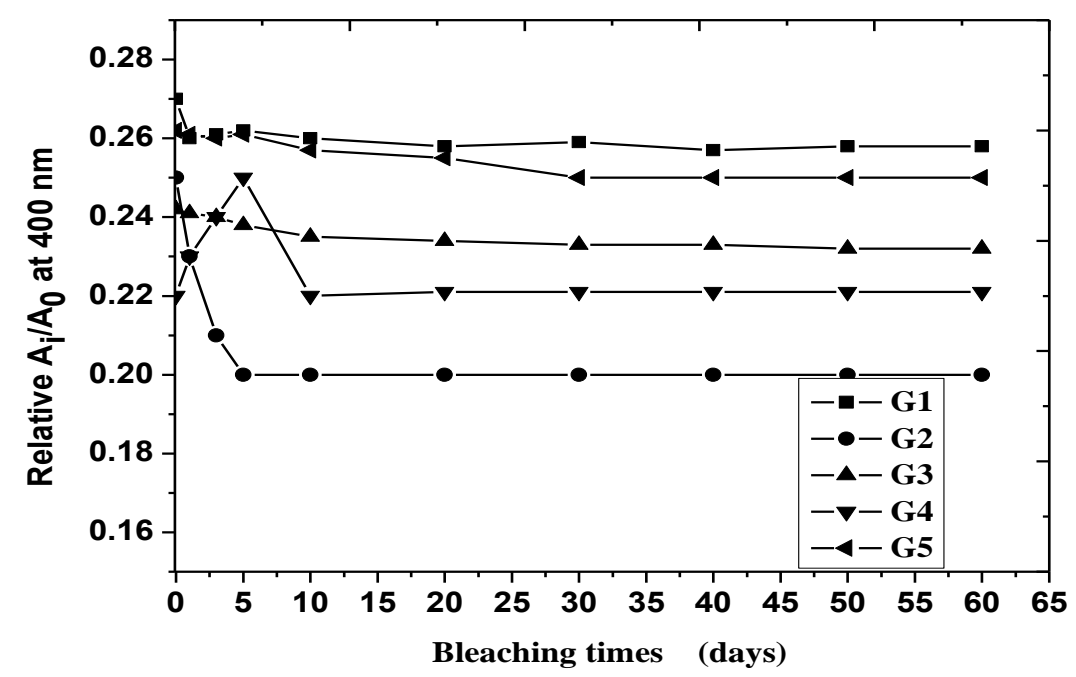

Fig. 7. Post irradiation stability for G1, G2, G3, G4 \& G5 irradiation with 30 kGy stored at different period of times at room temperature light in terms of change of relative absorbance.

\section{Optical energy gap}

Two types of optical transitions, i.e. direct and indirect, occur at the absorption edge. According to Tauc (1974), in many amorphous materials the variation of absorption coefficient with photon energy shows three regions. The first region which is also known as 'Tauc region' corresponds to high absorption from which optical energy gap can be calculated. This region is associated with inter band transitions i.e. it may correspond to transition of an electron belonging to an oxygen ion in an excited state. As a consequence of this, a marked sharp increase in the absorption coefficient $\alpha(v)$ will result. For Tauc's region, absorption coefficient is given in quadratic form which is discussed by Mott and Davis (1979) in more general form: $\alpha h v=\mathrm{B}\left(h v-\mathrm{E}_{\mathrm{opt}}\right)^{\mathrm{n}}$, (Duffy et al., 1976), where $h$ is the photon energy and $\mathrm{E}_{\mathrm{opt}}$ is the optical band gap. Here, $\mathrm{n}$ is an index that have different values depending upon the Egypt. J. Rad. Sci. Applic., Vol. 26, No. 1-2 (2013) 
mechanism of inter band transitions i.e. 2, 3, 1/2,1/3 values corresponding to indirect allowed, indirect forbidden, direct allowed and direct forbidden. By plotting $(\alpha h v)^{1 / 2}$ and $(\alpha h v)^{2}$ as a function of photon energy $h v$, optical band gaps for indirect and direct transitions can be determined respectively. The respective values of $E_{o p t}$ were obtained by extrapolating to $(\alpha h v)^{1 / 2}=0$ for indirect transitions and $(\alpha h v)^{2}=0$ for direct transitions (Uma et al., 2002 and Tauc, 1974). It can be seen that the band gap decreases from 4.15 to $3.48 \mathrm{eV}$ with increasing content of $\mathrm{MnO}_{2}$ as shown in Fig 10 for G1 and G4 for indirect transition and from 4.5 to $4.2 \mathrm{eV}$ for direct transition as illustrated in Table 1. The introduction of $\mathrm{MnO}_{2}$ will cause the P-O-P bonds breakage and appearance of (NBO) in the network. Shift of energy gap to lower energies can be due to the formation of NBO's. Moreover, the negative charge on NBO's has larger magnitude than on the BO. When the ionicity of oxygen atoms is increased by converting them from bridging to non-bridging, then the top of valence band is raised resulting in reduced energy gap. The change in optical band gap is attributed to the structural changes due to the different site occupancies by captions. Figs.8-10 shows the variations of band gap with the concentration of $\mathrm{MnO}_{2}$ for un-irradiated samples and irradiated samples. With the increase in crystallinity of glass, the band gap decreases as the absorption can occur at lower frequencies. The second region known as 'Urbach region' is exponential region due to the structural disorientations and randomness of the system. Disordered materials produce localized states in the band gap which results from exponential absorption tail. For small absorption coefficients $\left(\alpha<10^{-4} \mathrm{~cm}^{-1}\right)$, there is usually an Urbach tail where $\alpha(v)$ depends exponentially on the photon energy $h v$ as follows: $\alpha(v)=\alpha_{0} \exp \left(h v / \mathrm{E}_{\mathrm{e}}\right)$ where $\alpha_{0}$ is constant and $\mathrm{E}_{\mathrm{e}}$ is Urbach energy which is the width of the tails of localized states in the band gap representing degree of disorder in amorphous materials. $E_{\mathrm{e}}$ values are calculated from slopes of linear portion of the curve between $\ln (\alpha)$ against $h v$ as shown in the inset of Fig. 11. The exponential dependence of $\alpha(v)$ on photon energy depicts that the material obeys Urbach rule. Tauc et al. (1972) have reported that disordering can arise from transitions between the localized states in band edge tails where the density is assumed to fall exponentially. Many factors like dislocations, thermal vibrations and electric field of defects etc. can cause the tailing of energy states in the forbidden gap. The increase in Urbach energy with the increase of $\mathrm{MnO}_{2}$ content is again suggesting an increase in amorphousity as well as open structure of the glass due to the formation of non-bridging oxygen. In case of irradiated glasses the Urbach energy is even lower compared to non-

Egypt. J. Rad. Sci. Applic., Vol. 26, No. 1-2 (2013) 
irradiated samples Fig 12. indicating the change in NBO`s which is consistent with the results obtained from $\mathrm{E}_{\mathrm{opt}}$ calculations. Third region is the weak absorption tail produced from defects and impurities in UV spectra. The effect of gamma irradiation also takes place, the band gap decreases from 4.15 to 2.9 $\mathrm{eV}$ and from 3.84 to 2.8 for indirect transition for both G1 and G4 respectively also for all glass systems. The decrease of optical band gap is basically due to the increase of energy width of band tails of localized state. During gamma irradiation, the defects are created within the samples.

TABLE 1. Optical gap energy, Urbach's energy and optical basicity for unirradiated and irradiated glass

\begin{tabular}{|c|c|c|c|c|c|c|c|}
\hline \multirow{2}{*}{$\begin{array}{c}\text { Dose } \\
\text { kGy }\end{array}$} & $\begin{array}{c}\text { Band gap energy } \\
\text { (eV) for G1 }\end{array}$ & \multicolumn{2}{c|}{$\begin{array}{c}\text { Band gap energy } \\
\text { (eV) for G4 }\end{array}$} & $\begin{array}{c}\text { Urbach } \\
\text { energy (eV) }\end{array}$ & $\begin{array}{c}\text { Glass } \\
\text { sample }\end{array}$ & $\begin{array}{c}\text { O. Basicity } \\
\mathbf{A}_{\text {th }}\end{array}$ \\
\cline { 2 - 8 } & Indirect & Direct & Indirect & Direct & 0.90 & G1 & 1.58 \\
\hline $\mathbf{0}$ & 4.15 & 4.50 & 3.48 & 4.20 & 0.80 & G2 & 1.52 \\
\hline $\mathbf{0 . 3}$ & 3.90 & 4.30 & 3.40 & 4.10 & 0.73 & G3 & 1.66 \\
\hline $\mathbf{2}$ & 3.80 & 4.20 & 3.30 & 3.90 & 0.60 & G4 & 1.78 \\
\hline $\mathbf{2 0}$ & 3.00 & 3.75 & 3.00 & 3.70 & 0.52 & G5 & 2.18 \\
\hline $\mathbf{3 0}$ & 2.90 & 3.60 & 2.80 & 3.50 & 0.50 & -- & -- \\
\hline
\end{tabular}

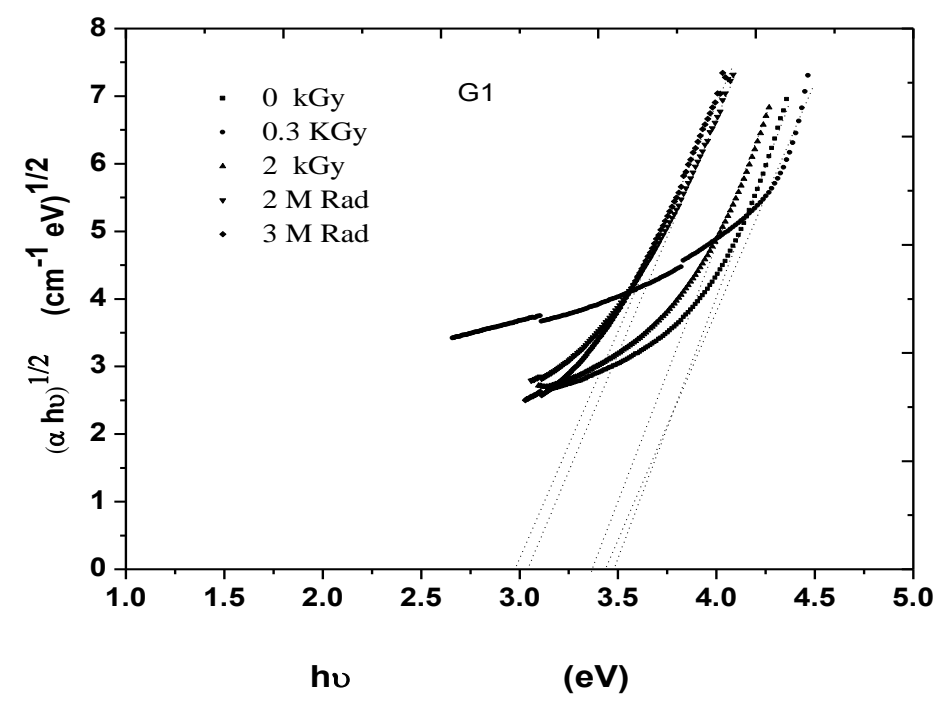

Fig. 8. The relation between energy $\mathrm{hv} \mathrm{eV}$ and $(\alpha \mathrm{E}) 1 / 2$ for glass $\mathrm{G} 4(\mathrm{R}$ : is the reability of fitting, best fitting $R= \pm 1$ ).

Egypt. J. Rad. Sci. Applic., Vol. 26, No. 1-2 (2013) 


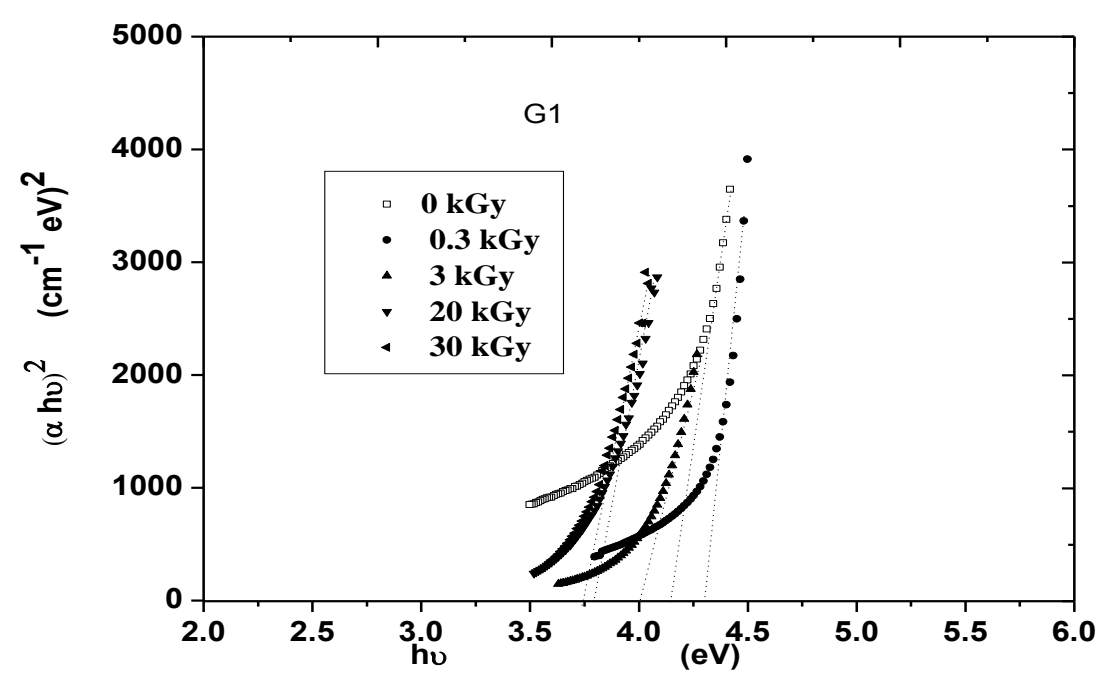

Fig. 9. The relation between Energy hveV and $(\alpha \mathrm{E})^{2}$ for glass $\mathrm{G} 4(\mathrm{R}$ : is the reability of fitting, best fitting $R= \pm 1$ ).

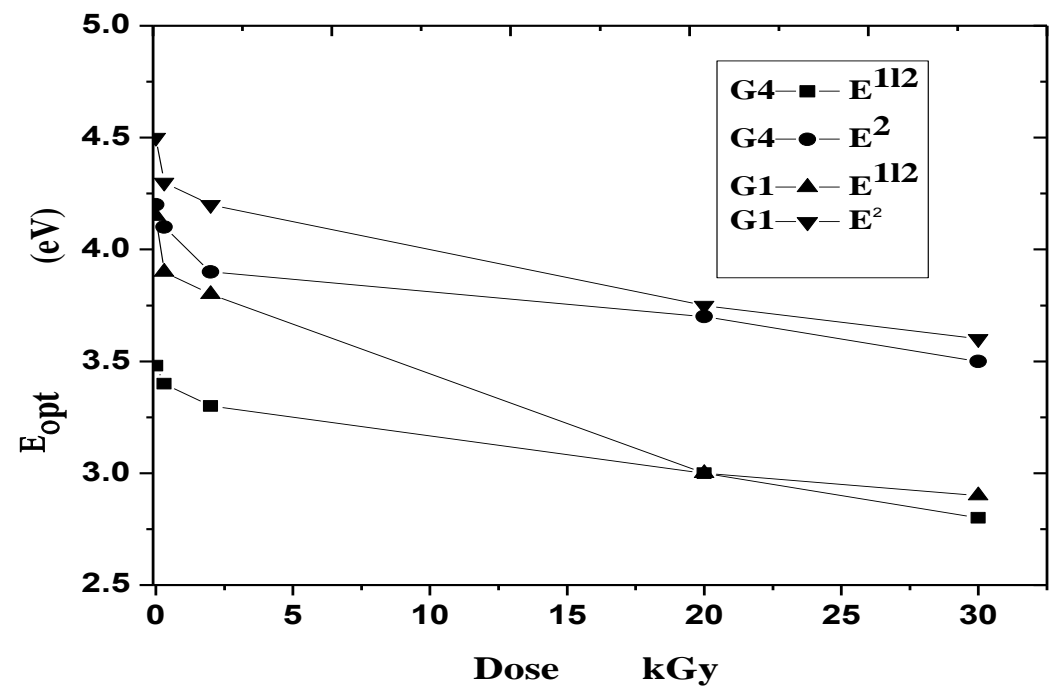

Fig. 10. Variation of optical band gap $E_{\text {op }}($ for $r=2,1 / 2)$ with different gamma doses for the glasses G1\& G2.

Egypt. J. Rad. Sci. Applic., Vol. 26, No. 1-2 (2013) 


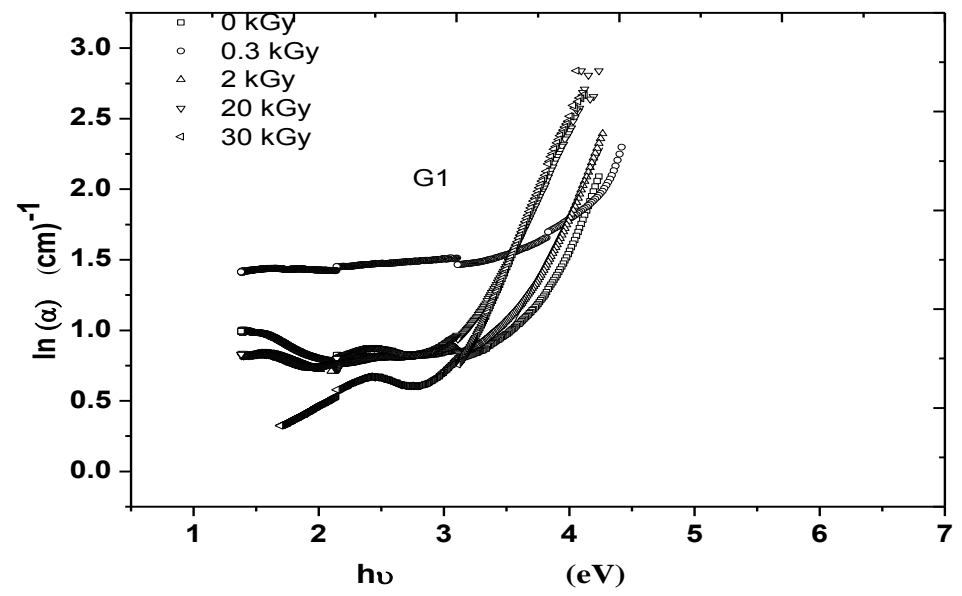

Fig. 11. Relation between absorption coefficient $\ln \alpha$ and energy hv for the prepared glass G1.

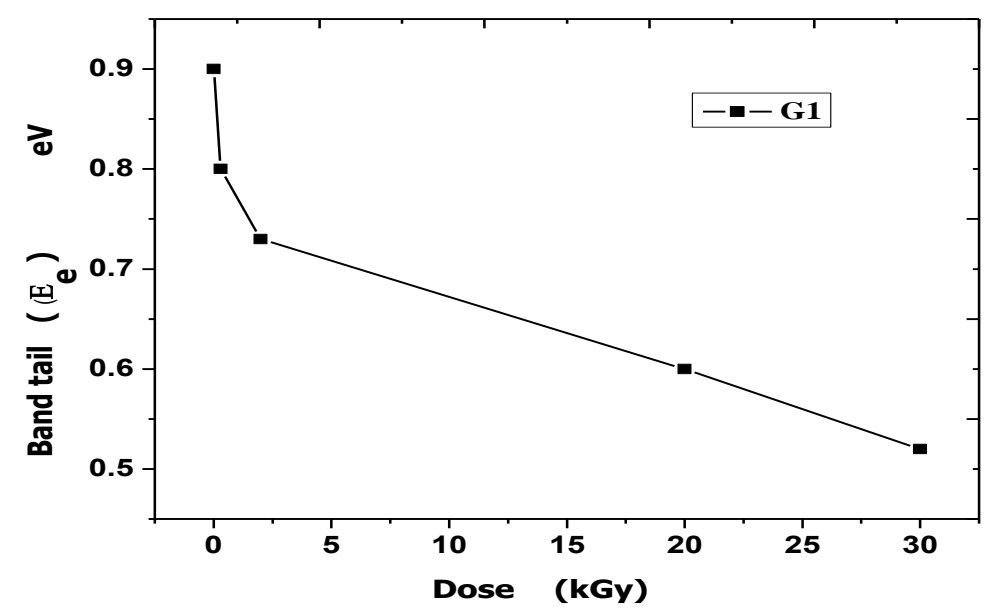

Fig. 12. Variation band tail Ee with gamma doses for the glass G1.

\section{Optical basicity calculations}

In the glass system, the tendency to form the structural units of oxide atoms can be estimated by optical basicity. In general, this tendency increases with increasing NBO's in the glass system. The cause of negative charge borne by an Egypt. J. Rad. Sci. Applic., Vol. 26, No. 1-2 (2013) 
ion arises from unequal sharing of electrons in a compound which can also be termed as resonance between covalent and ionic structures. Agarwal et al. (2004) reported that the ideal values of optical basicity can be predicted from the composition of the glass and the basicity moderating parameters of the various cations present. The theoretical values of optical basicity of the glass can be estimated using the formula (Urbach, 1953),

$$
\mathrm{A}_{\mathrm{th}}=\sum_{\mathrm{i}=1}^{\mathrm{n}} \mathrm{Z}_{\mathrm{i}} \mathrm{r}_{\mathrm{i}} / 2 \gamma_{\mathrm{i}}
$$

where, $\mathrm{n}$ is the total number of cations, $\mathrm{Z}_{\mathrm{i}}$ is the oxidation number of the $\mathrm{i}^{\text {th }}$ cation, $r_{i}$ is the ratio of the number of $i^{\text {th }}$ cations to the number of oxides present and and $\gamma_{i}$ is the basicity moderating parameter of the ith cation. $\gamma_{i}$ can be calculated from the following equation.

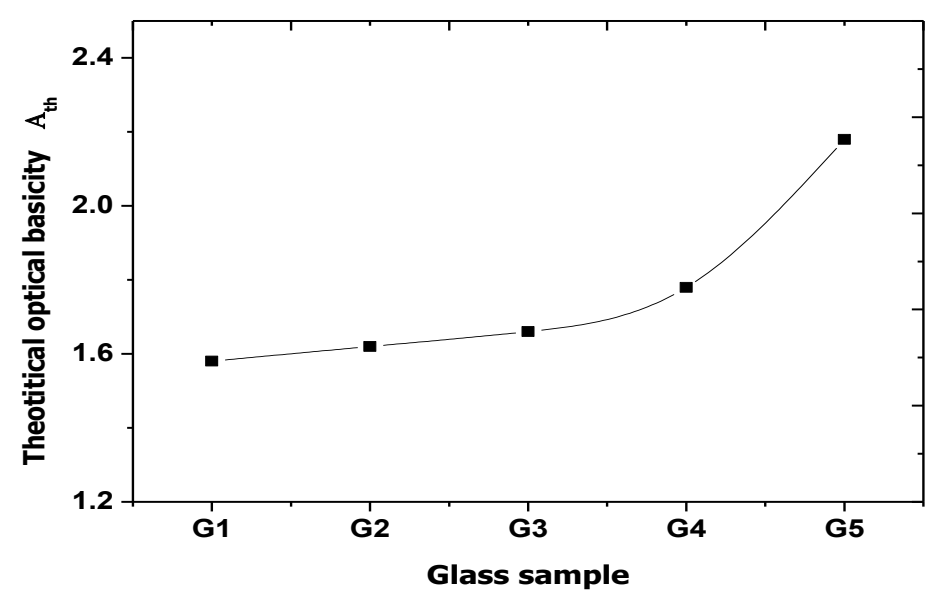

Fig. 13. Theoretical optical basicity for the studied glass samples G1,G2,G3,G4 and G5.

$$
\gamma_{i}=1.36\left(X_{i}-0.26\right)
$$

where, $X_{i}$ is the Pauling electronegativity of the cation. The variation of optical basicity with the increasing concentration of $\mathrm{MnO}_{2}$ is shown in Fig. 13, glass G5 has higher values of optical basicity due to higher number of NBO's in this glass. The increasing thermodynamic stability is associated with increasing charge on oxygen atoms. During irradiation of glasses the vibrations of phosphate and oxygen atoms introduce large scale disruption in the network via the conversion of bridging oxygen to non- bridging oxygen. The theoretical values of optical basicity $\left(\mathrm{A}_{\mathrm{th}}\right)$ were calculated for all glass samples and presented in Table 1.

Egypt. J. Rad. Sci. Applic., Vol. 26, No. 1-2 (2013) 


\section{Conclusion}

The addition of $\mathrm{MnO}_{2}$ in $\mathrm{PbO}-\mathrm{P}_{2} \mathrm{O}_{5^{-}} \mathrm{xMnO}_{2},(0<\mathrm{x}<1)$ glasses exhibit marked effect on their structural, optical and physical properties. Gamma irradiation produces induced defects generated from collective combination of trace iron impurities and $\mathrm{Mn}^{2+}$ ions, and these glasses show obvious shielding effect towards successive irradiation doses especially in the visible spectral region.

The $\mathrm{E}_{\mathrm{opt}}$ show a considerable decrease with increase of $\mathrm{MnO}_{2}$ content due to increase in number of NBOs. Consequently, the width of tails of the localized states in the band gap is observed to increase $\left(\mathrm{E}_{\mathrm{e}}\right)$ indicating more disorder in the glass structure. The band gap and Urbach energy is even lower for irradiated samples as compared to as cast glasses. Optical basicity calculations clearly depicted the increase of ionicity with increasing $\mathrm{MnO}_{2}$ content. The irradiated glasses exhibit band gap in the semiconducting range.

\section{References}

Paul, A. (1982) Chemistry of Glass, Chapman \& Hall, London, New York, p. 108.

Agarwal,A,Sth V.P,Gahlot, P. S., Khasa, S. and Chand, P. (2004) Effect of $\mathrm{Bi}_{2} \mathrm{O}_{3}$ on electron paramagnetic resonance, optical transmission and conductivity in vanadyl-doped $\mathrm{Bi}_{2} \mathrm{O}_{3} \cdot \mathrm{K}_{2} \mathrm{O} \cdot \mathrm{B}_{2} \mathrm{O}_{3}$ glasses Mat. Chem. Phys., 85, 215.

Bishay, A. (1970) Radiation induced color centers in multicomponent glasses. J. Non Cryst. Solids, 3, 54.

Doweidar, E., Moustafa, Y. MEl-Egili, K. and Abbas, I. (2005) Infrared spectra of $\mathrm{Fe}_{2} \mathrm{O}_{3}-\mathrm{PbO}-\mathrm{P}_{2} \mathrm{O}_{5}$ glasses. Vib. Spectrosc., 37, 91.

Duffy, J. A. and Ingram, M. D. (1976) An interpretation of glass chemistry in terms of the optical basicity concept. J. Non Cryst. Solids, 21, 373.

Ebrahim, S. and Antar, E. (2013) Band gap determination from diffuse reflectance measurements of irradiated lead borate glass system doped with $\mathrm{TiO}_{2}$ by using diffuse reflectance technique. Mat. Sci. App., 4, 324.

EIBatal, F. H., Azooz, M. A. and Elkheshen, A. A. (2009) UV-Visible and infrared spectra of gamma-irradiated transition metals-doped lead borate glasses. Trans. Ind. Cer. Soc., 68, 1.

El Batal, F. H., Marzouk, S. and Ezz-Eldin, F. (2011) UV-Vis and infrared spectroscopy of gamma-irradiated lithium diborate glasses containing $\mathrm{SeO} 2$. J. Mol. Structure, 986, 22.

Ghoneim, N., Marzouk, M., Daoud, T. and Ezzeldin, F. M. (2013) Spectroscopic properties of gamma irradiated $\mathrm{TiO}_{2}$ doped lithium phosphate glasses Ind. J .Phys., 87, 39.

Egypt. J. Rad. Sci. Applic., Vol. 26, No. 1-2 (2013) 
Ghoneim, N., Moustaffa, F., Zahran, A. and Ezz El Din, F. (1983) Gamma-ray interaction with lead borate and lead silicate glasses containing manganese. $J$. Am. Ceram. Soc., 66, 447.

Lell, E., Kreidl, N. J., Hensler, J. R. (1966) Radiation effects in quartz, silica and glasses. In: Burke, J.E. (ed.). Progress in Ceramic Sciences, Pergamon, Oxford 4, 1.

Marzouk, S. and ElBatal, F.H. (2006) Ultraviolet-visible absorption of gammairradiated transition metal ions doped in sodium metaphosphate glasses. Nucl Instrum Methods Phys Res B. 248, 90.

Marzouk, S. Y., Elalaily, N. A., Ezz-Eldin, F. M. and AbdAllah, W. M. (2006) Optical absorption of gamma-irradiated lithiumborate glasses doped with different transition metal oxides. Physica, B 382, 340.

Monke, D. and Ehrt, D. (2001) Radiation induced defects in different glasses demonstrated on a metaphosphate glass, Glass Sci. Technol., 74, 199.

Mott, N. and Davis, E. (1979) Electronic processes in non-crystalline materials. 2nd edn., Clarendon Press, International Series of Monographs on Physics, Oxford, UK.

Tauc, J. (1974) Amorphous and Liquid Semiconductors, Plenum Press, London and New York, p. 175.

Tauc, J. and Menth, A.(1972) States in the gap , J. Non-Cryst. Solids, 8, 569.

Uma, D. C., Sharma, A. K. and Rao, V. R. N. (2002) Electrical and optical properties of pure and silver nitrate -doped polyvinyl alcohol films. Materials Lett., 56, 167.

Urbach, F. (1953) The long-wavelength edge of photographic sensitivity and of the electronic absorption of solids. Phy. Rev., 92, 1324.

Weyl, W. A. (1959) Colored Glasses, Reprinted By Dawson`s of Pall Mall, London, 1, p. 68.

(Received: 15/09/2013;

accepted: 22/12/2013)

Egypt. J. Rad. Sci. Applic., Vol. 26, No. 1-2 (2013) 


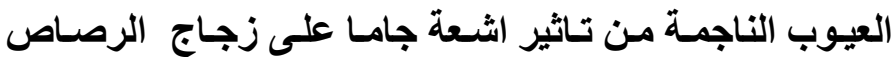 والفوسفات المطعم بالمنجنيز تيزيز \\ فتحى عز الدين و عنتر السعيد و محمود عبد الواحد الأهدل

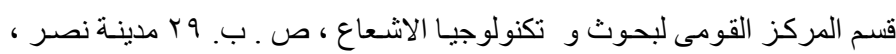

\begin{abstract}
تم عمل توليفة مـن زجـاج الفوسفات و الرصـاص المطعم بـالمنجنيز

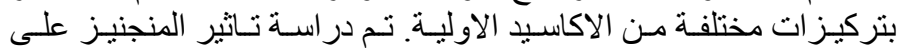

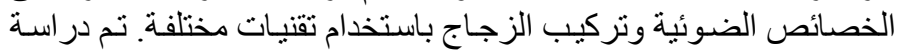

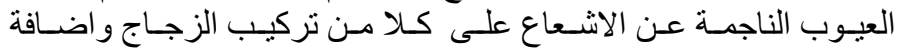
تركيز ات مختلفة من المنجنيز.

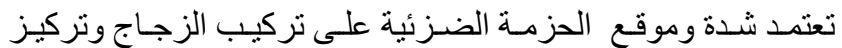

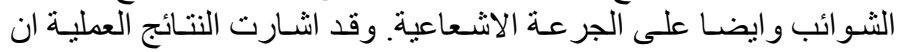

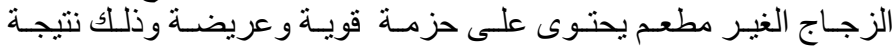

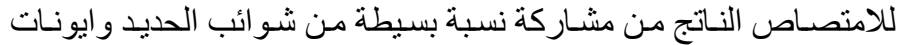

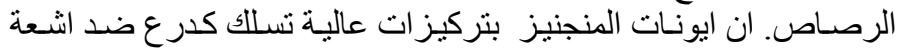

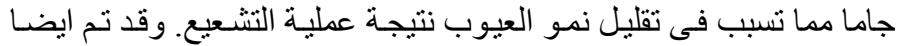

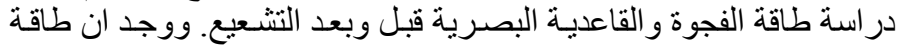

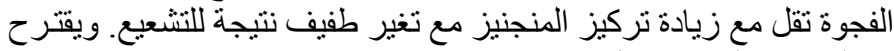

ان الية الانتقال هو انتقال غير مباثر الثر معر
\end{abstract}

Egypt. J. Rad. Sci. Applic., Vol. 26, No. 1-2 (2013) 